effectively reducing the number of responses required by rangers in Grand Canyon National Park, the PSAR Team saves the National Park Service over \$300,000 annually.

Christian Malcolm, MA/NREMT-P Hannah Heinrich, PhD Emily Pearce, BS/NREMT-P Grand Canyon National Park, AZ, USA

\section{Physiological Temperature Thresholds and Heat-Related Hiker Assists: Preventive Search and Rescue in Grand Canyon National Park}

Introduction.--Heat-related hiking emergencies in Grand Canyon National Park occur frequently and place great demand on resources. The Preventive Search and Rescue Team (PSAR) perform approximately 750 hiker assists and 300 search and rescue (SAR) missions annually.

Objectives.-This study examines hiker assist frequencies in correlation with maximum daytime temperatures in Grand Canyon National Park, with the goal of gathering information to improve the PSAR Team's strategy: to better utilize limited resources and provide a safer and more enjoyable National Park experience.

Methods.-Data was collected for this prospective study by PSAR rangers in 2011 and 2012 for all hikers who required assistance while hiking in Grand Canyon National Park. Inclusion criteria were created for heat-related hiker assists. The number of preventive actions, heat-related and non-heatrelated hiker assists was compared to average maximum daytime temperatures in Grand Canyon.

Results.-Heat-related hiker assists increased by $61.5 \%$ when maximum daytime temperatures were $\geq 95^{\circ} \mathrm{F}$. No correlation was found between non-heat-related hiker assists and temperature. Preventive actions remained consistent across all temperature ranges.

Conclusions.-The incidence of heat-related hiker assists is significantly higher at or above a temperature threshold of $95^{\circ} \mathrm{F}$, identifying a critical inflection point for temperaturerelated hiker safety. High temperatures increase risk for heatrelated illness or potential death. Individuals hiking in Grand Canyon National Park may therefore benefit from increased caution while hiking in temperatures at or exceeding $95^{\circ} \mathrm{F}$. Additionally, Preventive Search and Rescue rangers may benefit from heightened awareness, preparedness, and staffing on days exceeding this temperature threshold achieving higher safety standards for personnel.

Christian Malcolm, MA/NREMT-P

Hannah Heinrich, PhD

Emily Pearce, BS/NREMT-P

Grand Canyon National Park, AZ, USA

\section{Chaos in the Wilderness: Lifesaving Perfor- mance of Medical Teams in Austere Environments}

Introduction.-The provision of life-saving medical care in austere environments requires individuals working in teams to rescue patients, yet few studies measure trainee performance in these environments.

Objectives.-Our goal was to develop a competency-based curriculum for patient care providers using a chaotic, multipatient, and environmentally challenging environment.

Methods.-A 5-hour wilderness/emergency preparedness training (EPT) curriculum was developed by a statewide panel of experts including 9 learning objectives, 18 competencies and 34 performance objectives. Following brief didactic and small group sessions, inter-professional teams of 5-6 trainees were observed in a large patient simulator designed to recreate environmentally challenging (ie, flood evacuation), multipatient scenarios using trained patient actors. Successful completion of 16 individual and 18 team performance objectives were assessed by trained observers. Prior to training, team members completed a 24-question knowledge assessment, a demographic survey and a comfort level self-assessment. Following training, trainees repeated the 24 questions, selfassessment, and a course assessment.

Results.-One-hundred ninety-five participants completed the course between November 2012 and August 2013, including $90(46.1 \%)$ health professional students, 60 (30.8\%) physicians, $32(16.4 \%)$ nurses, $5(2.6 \%)$ health administrators, $3(1.5 \%) \mathrm{EMS} /$ fire personnel, $3(1.5 \%)$ environmental engineers, and $2(1.0 \%)$ law enforcement officials. Thirty-eight $(19.5 \%)$ reported $>3$ hours of wilderness/EPT each year while $157(80.5 \%)$ reported $\leq 3$ hours of yearly EPT. One-hundred ninety-five (73.3\%), 139 (52.2\%) and 66 (33.8\%) participants completed the pretest, posttest, and course assessment. The average percentage of correct answers between the pretest and posttest increased from 47.4 to 77.8 . $66(100 \%)$ reported the course relevant to care providers and 61 (92.4\%) highly recommended the course.

Conclusions.-Our competency-based wilderness/EPT curriculum used a large simulator to measure performance in a chaotic environment. Novice and experienced trainees improved knowledge and highly recommended the course. Further research is needed to assess the impact of the curriculum on individuals and teams.

Lancer A. Scott, MD Julie Teuber, BS Jamal Jones, BS Judy Staub, BS Andrew Seymore, BS Charleston, SC, USA 